\title{
Cyber Bullying and Traumatic Experiences: The Impact on Learning Disabilities
}

\author{
https://doi.org/10.3991/ijes.v6i1.8401 \\ Agathi Stathopoulou( $\left({ }^{\bowtie}\right)$ \\ Center for Diagnosis, Differentiation and Support, Athens, Greece \\ National Centre of Scientific Research "Demokritos", Athens, Greece \\ stathopoulou. fayyad@gmail.com \\ Zoe Karabatzaki, Dionisis Loukeris, Panagiotis Mantas \\ Ministry of Education, Research and Religious Affairs, Greece \\ National Centre of Scientific Research "Demokritos", Athens, Greece \\ Georgia Kokkalia, Athanasios S. Drigas \\ National Centre of Scientific Research "Demokritos", Athens, Greece
}

\begin{abstract}
The aim of our research is to investigate the effects of traumatic experiences that teens with learning disorders had to go through. The sample of our study is consisted of 160 high school students who were referred in a web line evaluation form, due to low school performance. The research tool that was used was ACHENBACH's self-report questionnaire for children and teenagers and more specifically the subscales for anxiety-depression and depressionwithdrawal. Frequencies, percentages of responses and means have been calculated. An analysis of variance (one way anova) to assess the differences in the averages of students' responses to the variable "experiencing a traumatic event" was also performed. The results showed that there are significant differences in the level of statistical significance $p<0,01$ between the means of students who say they have experienced a traumatic event and those who report that they haven't. Particularly decisive traumatic experience for the students' mentality seems to be the in-school violence received by students and the death of a loved one. Application features that have to do with the cyber bullying are also presented briefly.
\end{abstract}

Keywords — cyber bullying, new technology, psychological problems, trauma

\section{Introduction}

Along with connectedness to family, connectedness to school during adolescence has emerged as a key area for building protective factors for positive educational outcomes and lower rates of health-risk behavior well being. Young people who are not engaged with learning or who have poor relationships with peers and teachers are more likely to use drugs and engage in socially disruptive behaviors, report anxiety 
and depressive symptoms, have poorer adult relationships, and fail to complete secondary school. Therefore, the potential consequences for young people of becoming disconnected from school are far reaching [1].

Negative school experiences largely account for young people becoming alienated or disconnected from school [2]. Similar research focusing on connectedness to school emphasizes the importance of the quality of relationships (peer and teacher) on engagement in learning, and on health and well being. Such experiences highlight different social experiences including, for example, being bullied, not getting along with teachers, feelings of not belonging, not doing well at school, and feeling under stress. Schools are accessible and relatively stable sites within which to locate interventions to promote adolescent connectedness at a time of multiple transitions, during which identity and relationships with family, peers, and school change [3]. Doing so may bring about better educational and health outcomes. While substantial research has been conducted both from health and educational perspectives, there is clearly a need to better understand what affects connectedness to school, how we can effectively measure this, and how and when we can best intervene [4].

Furthermore, modern technology is continuously evolving, and in recent times, it has manifested itself in a very serious social problem, namely cyber bullying. Unfortunately little attention is given to this global problem by institutions of higher learning, teachers, parents and emergency service providers. The depressive effect of cyber bullying prevents students from excelling in their studies [5] as bullying in schools and universities are causing unimaginable problems to students, parents and to educational institutions. So, little has been done to help those victims who are continuously trapped in the name of modernization and digitalization. However, researchers agree that the stressful impact of bullying is escalating with the rapid expansion of technological advancement because many students who are victims of cyber bullies suffer silently and they are reluctant to complain to the authorities or their parents owing to the social stigma attached to victims of bullies. As such, parents, teachers and institutional authorities have to be on the lookout for such occurrences [6].

Overall, many researchers agree that young people's experiences of early secondary school and their relationships at school continue to predict their moods, their substance use in later years, and their likelihood of completing secondary school. Students with good school and good social connectedness are less likely to experience subsequent mental health issues and be involved in health risk behaviors, and are more likely to have good educational outcomes. School connectedness, however, includes relationships with peers, teachers, and learning. Thus, the challenge is not whether school or social connectedness is more important, but how we can promote both school connectedness and social connectedness in forms that promote learning and well being without traumatic experiences and learning difficulties [7].

In the light of the above statements, in this paper we will give a brief overview of some representatives' studies that explore the role of new technology in a really serious traumatic experience as cyber bullying while we will try to investigate how decisive traumatic experience for the students' mentality may effect their school performance. As a result, the outcomes of our study that analyzed the relationship between 
traumatic experience and learning disabilities of secondary school pupils are going to be presented thoroughly.

\section{Wound and Puberty}

Freud was the first to describe the mental trauma as "a righteous in the defense mechanisms of the individual" and in 1926 he stated that the person at the time of the traumatic experience is characterized by a sense of total disability [8]. Traumatic experience can be a formative influence in emotional and cognitive development. It is estimated that $25 \%$ of the children have experienced a traumatic event until the 16 years [9]. Many studies report that about 15 to $43 \%$ of girls and 14 and $43 \%$ of boys have experienced a traumatic event by 16 ages. Of these, 3 to $15 \%$ of girls and 1 to $6 \%$ of boys may appear intense psychological problems. The intensity of psychological problems is high and reaches severe levels of dysfunction in $100 \%$ of children and adolescents who witnessed domestic violence, $90 \%$ in the case of children and adolescents who have been sexually assaulted, $77 \%$ for children who have been armed school environment and $35 \%$ of children and adolescents exposed to violence within the community living [10],[11], [12],[13],[14]. Many of these children achieved to overcome the wound, adapt and integrate their experience and develop naturally. In some, however, the intensity of psychological problems reaches clinical levels causing serious dysfunctions in their daily lives and significant cognitive deficits [15], [16]. Among the most common symptoms are those that affect: a) cognitive perception (they can not stop thinking about the traumatic experience or feel that everything around them is precarious), $\beta$ ) the emotional nature of the child (loneliness, nightmares, anxiety and horror) c) socio-behavioral disorders (aggressive and abusive behavior, rejection of parental authority and that of teachers, denial of all kinds of activity, d) cognitive behavior disorders (attention disruption and low school performance) and d) physical symptoms (headaches, stomach anxiety and hypochondriasis) [17],[18],[19].Children usually avoid specific thoughts, positions, games and behaviors that remind them of the traumatic experience. They can interrupt pleasant activities or do not make unknown situations to avoid feelings of fear and anxiety. This type of traumatic avoidance can affect daily activity or generalize into a more phobic behavior by inhibiting both the cognitive development and the positive social experiences of the child [20].

\section{$3 \quad$ Applications Features and Cyber-Bullying in Schools}

Technological developments including smartphones, social media, and mobile apps have changed the way individuals interact with each other. Bechtoldt,et al. [21] assert that today's teenagers use features to share images and videos (e.g., Instagram, Keek), send limited-time messages (e.g., Snapchat), and for hyper local communication (e.g., Yik Yak, Whisper) significantly more than a decade ago. Correspondingly, cyber bullying now occurs in forms that were impossible or uncommon a few years prior. Cyber bullying is defined as: "When the Internet, cellphones or other devices are used 
to send or post text or images intended to hurt or embarrass another person". According to a National Crime Prevention Council report, more than $40 \%$ of US teenagers have reported being cyber bullied. This is especially worrying, as multiple studies found that cyber bullying victims often have psychiatric and psychosomatic disorders and a British study found that nearly half of suicides among young people were related to bullying. These factors underscore an urgent need to understand, detect, and ultimately reduce the prevalence of all cyber bullying [22].

Exposure to bullying, physical violence and sexual abuse may result in an array of negative outcomes, such as poor mental health, physical health and lower sense of well being [23]. This study as it was mentioned and above is mainly focused on potential negative consequences of bullying, violence and death of a loved one in terms of academic achievement. As it is well known, adolescents' academic achievements are of great importance for prospective school choices and consequently a long-term career [23]. Previous researches have found that bullied and abused children or adolescents perform worse in school compared with their no abused peers [24]. Few studies on bullying have investigated the influence of school-level factors on individual academic performance and thus research has indicated that school-level factors may explain $10 \%$ of the variance in individual grades [25]. Konishi et al. [26] conducted one of the few multilevel studies in this area and found that school-level bullying was associated with lower grades. This stresses the need to simultaneously investigate individual and contextual influences on students' academic achievement. For victims of abuse, the social environment becomes especially important because it may serve as a protective factor against some of the negative consequences of the abuse and potentially affects the adolescent's development in a positive way [27]. On the other hand, a negative school climate may contribute to a negative personal development [27]. Additionally, a growing body of literature shows that victims and perpetrators of cyber bullying are at greater risk for experiencing a myriad of mental health problems including depressive symptoms, suicidal ideation, and suicide attempts. Despite awareness of the mental health risks associated with cyber bullying, few studies have applied a theoretical framework to understanding the perpetration of cyber bullying [28].

As a result of the above statements, in order to inform prevention/intervention of cyber bullying behaviors, the Theory of Reasoned Action is a tool that was developed for this reason. Heirman and Walrave [29] defined cyber bullying as "intentionally hurting or harming someone you personally know online or offline through the use of digital media such as the Internet or mobile phone,', (p. 616). Empathy toward cyber bullying victims was also included in the models. Participants completed the cyber bullying perpetration scale of the Cyberbul- lying Experiences Survey [30] that assesses four types of cyber bullying (deception, malice, public humiliation, and unwanted contact). Across all four models, results showed that lower empathy toward cyber bullying victims predicted more favorable attitudes toward cyber bullying perpetration, more favorable attitudes toward cyber bullying predicted higher intentions to cyber- bully, and higher cyber bullying intentions predicted more frequent perpetration of cyber bullying behaviors. Injunctive norms regarding cyber bullying (e.g., perception of peers' approval of cyber bullying perpetration) predicted intentions to 
engage in malice and unwanted contact behaviors. The results demonstrate that the TRA is a useful framework for understanding cyber bullying perpetration [30].

Moreover another research team states that social networking sites provide a fertile medium for bullies, and teens and young adults who use these sites are vulnerable to attacks. Through machine learning, the team says that it is easier to detect language patterns used by bullies and their victims, and develop rules to automatically detect cyber-bullying content. The data that was used for this project was collected from the web- site Formspring.me, a question-and-answer formatted website that contains a high percentage of bullying content. The data was labeled using a web service, Amazon's Mechanical Turk. Additionally, it was used the labeled data, in conjunction with machine learning techniques provided by the Weka tool kit, to train a computer to recognize bullying content. Both a $\mathrm{C} 4.5$ decision tree learner and an instance-based learner were able to identify the true positives with $78.5 \%$ accuracy. By recording the percentage of curse and insult words within a post, we were able to correctly identify $78.5 \%$ of the posts that contain cyber bullying in a small sample of Form spring data. The final results indicate that such features do a reasonable job of identifying cyber bullying in Form spring posts and also that there is plenty of room for improvement on this timely and important application of machines learning to web data [31].

Furthermore, because of the rising popularity of communications taking place in social networks, an inconsiderable part of interpersonal interactions of young people is performed online. As an effect, new risks and threats, such as cyber bullying, stalking and online grooming, emerge. The main affected group in this context is children between 12 to 17 years old [32] (eMarketer, 2013). A recently conducted team developed a research agenda for a Facebook Watchdog application pursuing the aim to detect the above-mentioned threats to improve the situation. The research supports the idea that threat indications are determined by image analysis, social media analytics, and text mining techniques in order to raise awareness about ongoing attacks and to provide assistance for further actions [33]. More specifically, the developers highlighted open research areas, which are required to develop a Facebook Watchdog app aiming at protecting adolescents against bullying and grooming attacks. They suggested a modular implementation enabling an easy way for extending the Watchdog with new modules that facilitate the exchange between research groups interested in the topic. Particularly important is thought the development of an evaluation matrix based on the weighted Facebook Watchdog modules. Also, in order to make more reliable statements about human behavior, the participation of social workers and young people themselves during the development process is thought necessary. Lastly, the project team believes that the weighted evaluation matrix establishes the basis for combining several image processing, text mining, and social analytics modules to detect cyber bullying and online grooming behavior [33].

Last but not least, another study investigated the influence of newer mobile app features like frequent sharing of images and videos, limited-time messages, and hyper local communication on cyber bullying in high school settings. Data analysis suggests that emerging app features play a significant role in how cyber bullying takes place in school settings. Specifically, the researchers found that differences in users' understanding of ephemerality can lead to scenarios where one party in a conversation may 
handle much more power than the other, and can exploit this to their advantage. Additionally, students are more directly affected by visual content, as it can be used as evidence or to reinvigorate arguments and as a result students are sophisticated enough to hold app designers responsible for the consequences of use of their apps. These findings, according to the researchers, have broaden our understanding surrounding the complex interplay between novel app-features and cyber bullying in school settings and pave the way for future app design refinements, as well as intervention studies [34].

\section{$4 \quad$ Methodology of our Research}

\subsection{Purpose of our Research}

The aim of our study was to investigate the relationship between traumatic experience and learning disabilities of secondary school pupils.

\subsection{Main research question}

The main research question that we were concerned about was whether there is a relationship between the appearance of learning disabilities of secondary school students and the experience of a traumatic event.

\subsection{Data collection}

Questionnaire Youth Self Report [35] was the instrument used in collecting the data . In particular, the questions of subscales "anxiety/depression" and "withdraw$\mathrm{al} /$ depression. In addition the students had access to an online form that was installed in their school to record demographics data and experiencing a possible traumatic event.

\subsection{Participants}

The survey involved 160 pupils aged 12-17 years studying in Secondary General and Vocational Secondary Education Schools in Athens who came to Center of Assessment and Support due to their learning disabilities. For the same students, we received some information from a online form that was installed in their school. Of the pupils 101 were boys and 59 were girls. Three (3) pupils were 12 years old, 30 pupils were 13 years old, 28 were 14 years old, 34 were 15 years old, 46 were 16 years old and 19 were 17 years old. About the class they were attending, 24 pupils were in first grade, 27 pupils attending second grade, 23 pupils were studying at the third grade, 39 pupils were studying in the 1st Lyceum, 30 pupils were studying in the 2st Lyceum and 17 pupils were studying in the 3st Lyceum. 


\subsection{Procedure}

We collected our data from October of 2016 to May of 2017. Each participant had completed an online form that was installed in his school. The pupils who participated had visited Center of Assessment and Support due to learning difficulties. The pupils in a special session completed the questionnaire Youth Self Report on a tablet that was made available to them after they and their parents were asked.

\subsection{Statistical analysis}

Statistical analysis of the data was carried out with the SPSS 23 statistical package. The frequencies and percentages of answers to Achenbach [35] self-report questionnaires for children and adolescents, as well as the student's statements regarding the traumatic event were measured. Our results are presented in the form of graphs and tables.

\subsection{Results}

Figure 1 shows the rates of student responses in the self- report questionnaires for children and adolescents

The traumatic experiences of these students were: threatening illness $(6,9 \%)$, family death $(5,6 \%)$, serious family conflicts - ugly divorce $(4,4 \%)$, chronic neglect and non-communication with the father $(8.8 \%)$ and cyber bullying $(2.5 \%)$. While $71.9 \%$ did not report any traumatic experience

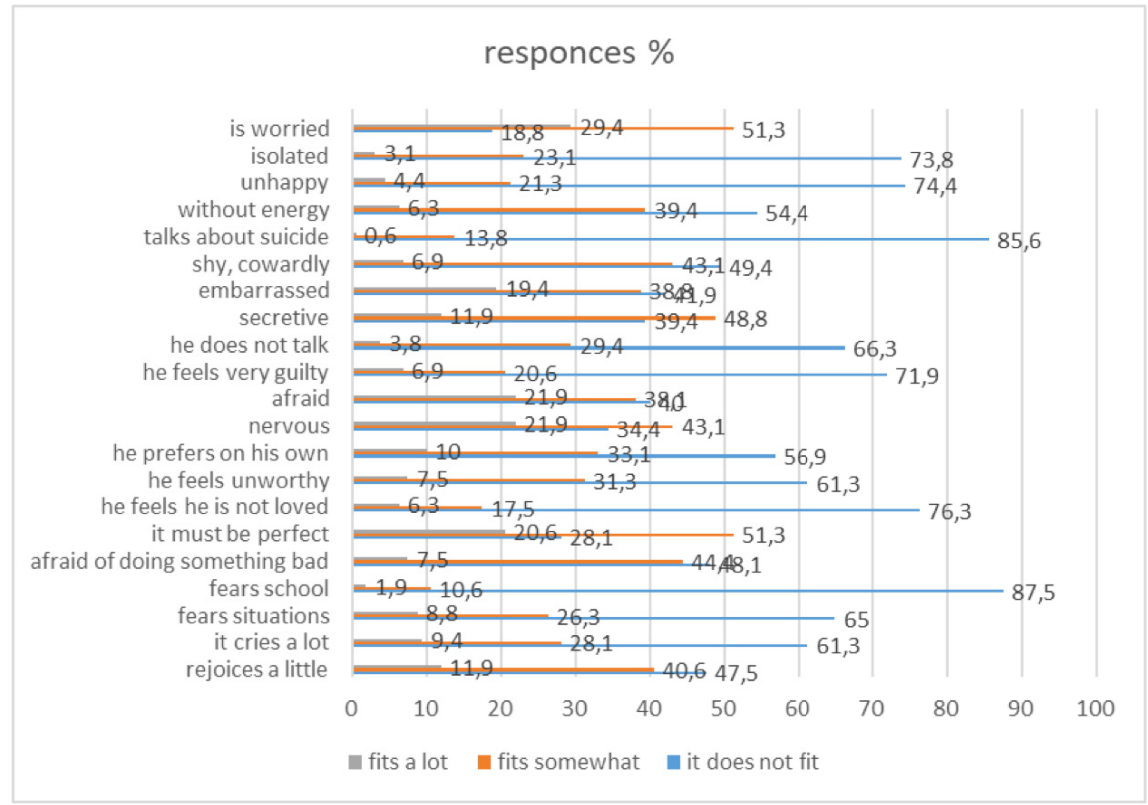

Fig. 1. Response rates in the self-report questionnaire for children and adolescents 
4.8 Correlations Between the Questions from The Youth Self Report Questionnaire And The Variable The Variable Traumatic Event Experience

Table 1 presents the correlations between the self-report questionnaires with variable traumatic event experience ( $* * \mathrm{P}<0.01-* \mathrm{P}<0.05$ ). (Only results that were statistically significant)

Table 1. Correlation of questions with variable traumatic event experience

\begin{tabular}{|l|l|l|}
\hline \multicolumn{2}{|c|}{ Variables } & Traumatic event experience \\
\hline rejoices a little & Pearson Correlation &, $202^{*}{ }^{* *}$ \\
\hline afraid of doing something bad & Pearson Correlation &, $236^{*}$ \\
\hline he feels he is not loved & Pearson Correlation &, $173^{* *}$ \\
\hline he feels unworthy & Pearson Correlation &, $224^{* *}$ \\
\hline he prefers on his own & Pearson Correlation &, $220^{* *}$ \\
\hline he thinks of suicide & Pearson Correlation &, $209^{* *}$ \\
\hline without energy & Pearson Correlation &, $167^{*}$ \\
\hline Unhappy & Pearson Correlation &, $311^{* *}$ \\
\hline Isolated & Pearson Correlation &, $216^{* *}$ \\
\hline
\end{tabular}

\subsection{Analysis of variance of self-report questionnaire for children and adolescents on the occurrence of a traumatic event}

Table 2 presents the analysis of variance of questions in the self-report questionnaire for children and adolescents on the occurrence of a traumatic event (one way anova). Only results that were statistically significant.

Table 2. Analysis of variance of Self-report questionnaire for children and adolescents on the occurrence of a traumatic event.

\begin{tabular}{|c|c|c|c|c|c|c|}
\hline & & $\begin{array}{l}\text { Sum of } \\
\text { Squares }\end{array}$ & df & $\begin{array}{l}\text { Mean } \\
\text { Square }\end{array}$ & $\mathbf{F}$ & Sig. \\
\hline \multirow{2}{*}{ embarrassed } & Between Groups & 7,877 & 5 & 1,575 & 2,958 &, 014 \\
\hline & Within Groups & 82,023 & 154 &, 533 & & \\
\hline \multirow{2}{*}{$\begin{array}{l}\text { he thinks of suicide } \\
\text { without energy }\end{array}$} & Between Groups & 2,401 & 5 & ,480 & 3,698 &, 003 \\
\hline & Within Groups & 19,999 & 154 &, 130 & & \\
\hline \multirow{2}{*}{ Unhappy } & Between Groups & 7,108 & 5 & 1,422 & 4,144 &, 001 \\
\hline & Within Groups & 52,836 & 154 & ,343 & & \\
\hline \multirow{2}{*}{$\begin{array}{l}\text { he thinks of suicide } \\
\text { without energy }\end{array}$} & Between Groups & 13,671 & 5 & 2,734 & 12,410 &, 000 \\
\hline & Within Groups & 33,929 & 154 &, 220 & & \\
\hline \multirow{2}{*}{ Unhappy } & Between Groups & 9,407 & 5 & 1,881 & 8,575 &, 000 \\
\hline & Within Groups & 33,787 & 154 &, 219 & & \\
\hline
\end{tabular}




\section{$5 \quad$ Multiple Comparisons of Averages}

For the statement: "I'm afraid to go to school" in the self-report questionnaire, the students who are victims of cyber bullying have a higher average than the students without reporting traumatic experience, the students who have experienced intrafamily conflicts- ugly divorce and students who have experienced neglect and noncommunication with a father. For the statement: "I'm afraid to think or do something bad", students who are victims of cyber bullying have a higher average than students without reporting traumatic experience, students who have experienced a threatening illness, inter-family conflicts-ugly divorce, and students who have experienced neglect and non-communication with a father. For the statement: "I feel inferior", students who have experienced neglect and non-communication with a father have a higher average than students without reporting traumatic experience. For the statement: "I prefer to be myself", students who have experienced the death of a family member show a higher average than the students without reporting traumatic experience. For the statement: "I'm easily embarrassed", students who have experienced neglect and non-communication with fathers have a higher average than students who have experienced family conflicts - ugly divorce. For the statements: "I think of suicide" and "I have no energy", students who have experienced family member death show a higher average than students without reporting traumatic experience. For the statement: "I feel unhappy" students who have experienced family member death show a higher average than the students without reporting traumatic experience and students who have experienced a threatening illness, inter-family conflicts-ugly divorce, and cyber-bullying students. Also, students who have experienced neglect and non-communication with a father have a higher average than students without reporting traumatic experience. For the statement: "I prefer to be myself rather than others", students who have experienced family member death show a higher average than the students without reporting traumatic experience, students who have experienced a threatening illness, domestic conflicts-ugly divorce, and neglect and noncommunication with a father. Also, students who have experienced neglect and noncommunication with a father have a higher average than students without reporting traumatic experience.

\section{Conclusion}

The results of our study show that the highest response averages are found in groups of adolescents who are victims of cyber-bullying, who have experienced family member death and neglect and non-communication with the father. Cyber bullying has been defined as 'an aggressive act or behavior that is carried out by the use of electronic means by a group or an individual repeatedly and over time against a victim who cannot easily defend himself [36]. Hence cyber bullying is a systematic abuse of power, which occurs through the use of information and communication technologies. Recent studies have investigated cyber bullying via a range of more specific media. They present seven main media ways described by secondary school 
pupils: mobile phone calls, text messages, picture/video clip bullying, e-mails, chat room, instant messaging, and websites [37]. When victims manage to defend themselves, negative psychological effects are diminished. However, when a victim finds no help or support, then the phenomenon can become particularly negative and the consequence on the victim's mental health extremely pernicious [38]. Studies showed that internalized fear might accompany the feeling of being defenseless, while an angry and reactive fear may feed a stress reaction. Stress, itself associated with reactive emotions such as anger, may support an attitude of either confrontation or avoidance. Frequently cyber bullying victims experience negative feelings over which they have little control and which affect their well being and influence in the school and wide social environment [39]. Furthermore researches demonstrated a link between suicidal ideation and experience with bullying and cyber bullying victimization [40]. Youth suicide is a significant public health concern. It is the third leading cause of death among young people. Review of many studies found a consistent association between being bullied and suicidal thoughts among youth. Furthermore, both perpetrators and targets of bullying and cyber bullying are at higher risk of depression, suicide ideation, and suicide attempts than adolescents not involved in bullying [41]. Additionally, victims of cyber bullying consistently report academic problems in relation to the preoccupation with the cyber bullying event. Students illustrated a sudden drop in their grades, increased absences and tense for social isolation, and emergent perceptions that school is no longer safe. Other serious academic problems such as cutting class, accumulating detentions and suspensions, and delinquent behavior are also reported. Decrements in academic performance can be credited to victims' poorer concentration and higher levels of frustration with the bully and situation [42].

Sample groups, who have experienced family member death and neglect and noncommunication with the father, have high averages in responses that particularly refer to feelings of isolation and misery. The results of the study confirm the international literature that claims that teenagers during their lamentation experience feelings of withdrawal and isolation from their normal activities. The findings are consistent with the international literature that claims that the teen mourns at intervals, which is due to his lack of strength to experience feelings of pain and sadness for a long time [43]. Also neglecting and not communicating with the father causes feelings of inferiority, isolation and misery. The absence of a parental pattern, at the time when the teen is experiencing a storm of both biological and social changes towards adulthood, creates a variety of negative emotions [44], [45].

\section{$7 \quad$ References}

[1] Blum RW, Libbey HP, School connectedness - strengthening health and education outcomes for teenagers, J School Health 2004; 74: 231-2 https://doi.org/10.1111/j.17461561.2004.tb08278.x

[2] Libbey HP.,Measuring student relationships to school: Attachment, bonding, connectedness, and engagement, School Health 2004, 74: 274 - 82 https://doi.org/10.1111/j.17461561.2004.tb08284.x 
Paper-Cyber Bullying and Traumatic Experiences: The Impact on Learning Disabilities

[3] Resnick MD, Bearman PS, Blum RW, et al., Protecting adolescents from harm: Findings from the National Longitudinal Study on Adolescent Health, JAMA 1997, 278:823-32 https://doi.org/10.1001/jama.1997.03550100049038

[4] Bond L, Carlin JB, Thomas L, et al. Does bullying cause emotional problems? A prospective study of young teenagers Br Med J 2001, 323:480 - 4 https://doi.org/10.1136/bmj.323. $\underline{7311.480}$

[5] Newman, Michelle G., et al. A review of technology-assisted self-help and minimal contact therapies for anxiety and depression: is human contact necessary for therapeutic efficacy?, Clinical psychology review 31.1, 2011, 89-103

[6] Hampton, Keith, et al.,Social networking sites and our lives, Pew Internet \& American Life Project 16, 2011,1-85

[7] Bond, Lyndal, et al., Social and school connectedness in early secondary school as predictors of late teenage substance use, mental health, and academic outcomes, Journal of Adolescent Health 40.4, 2007, 357-359

[8] Streets, M. D., and M. Gerald, The homicide witness and victimization; PTSD in civilian populations: a literature review, Jefferson Journal of Psychiatry 8.1, 1990,12

[9] Costello, E. Jane, et al, The prevalence of potentially traumatic events in childhood and adolescence, Journal of traumatic stress 15.2, 2002, 99-112

[10] Pynoos, Robert S., and Spencer Eth, Witness to violence: The child interview, Journal of the American Academy of child Psychiatry 25.3, 1986, 306-319

[11] Pynoos, Robert S., et al., in School-age Children, Arch Gen Psychiatry 44, 1987, $1057-$ 1063 https://doi.org/10.1001/archpsyc.1987.01800240031005

[12] Pynoos, Robert S., Alan M. Steinberg, and John C. Piacentini, A developmental psychopathology model of childhood traumatic stress and intersection with anxiety disorders, Biological psychiatry $46.11,1999,1542-1554$

[13] Neuner, Frank, et al. Post - tsunami stress, A study of posttraumatic stress disorder in children living in three severely affected regions in Sri Lanka, Journal of traumatic stress 19.3 2006,339-347 https://doi.org/10.1002/jts.20121

[14] Spertus, Ilyse L., et al., Childhood emotional abuse and neglect as predictors of psychological and physical symptoms in women presenting to a primary care practice, Child abuse \& neglect27.11, 2003,1247-1258

[15] March, John S., et al., Cognitive - Behavioral Psychotherapy for children and adolescents with posttraumatic stress disorder after a single - incident stressor, Journal of the American Academy of Child \& Adolescent Psychiatry 37.6, 1998, 585-593

[16] Nader, Kathleen O., and Lynn A. Fairbanks, The suppression of re-experiencing: Impulse control and somatic symptoms in children following traumatic exposure Anxiety, stress, and coping 7.3, 1994, 229-239

[17] Qouta, Samir, et al, Does war beget child aggression? Military violence, gender, age and aggressive behavior in two Palestinian samples Aggressive behavior 34.3, 2008, 231-244

[18] Altawil, Mohamed, David Harrold, and Muthanna Samara, Children of war in Palestine, Children in War 1.5, 2008, 5-11

[19] Stathopoulou, A., G. Papadatos, and D. Anagnostopoulos The psychological reactions of children and adolescents who experienced bombing and political and military conflict in Palestine, ARCHIVES OF HELLENIC MEDICINE 33.1, 2016, 64-72

[20] Morris, Tracy L., and John S. March, eds, Anxiety disorders in children and adolescents, Guilford Press, 2004

[21] Bechtoldt, Myriam N., et al.,The primacy of perceiving: Emotion recognition buffers negative effects of emotional labor, Journal of Applied Psychology 96.5, 2011, 1087 
[22] Li, Qing, Cyberbullying in schools: A research of gender differences, School psychology international 27.2, 2006, 157-170

[23] Juvonen, Jaana, Adrienne Nishina, and Sandra Graham, Peer harassment, psychological adjustment, and school functioning in early adolescence, Journal of educational psychology $92.2,2000,349$

[24] Rothon, Catherine, et al., Can social support protects bullied adolescents from adverse outcomes? A prospective study on the effects of bullying on the educational achievement and mental health of adolescents at secondary schools in East London, Journal of adolescence 34.3, 2011, 579-588

[25] Strøm, Ida Frugård, et al, Violence, and bullying and academic achievement: A study of 15-year-old adolescents and their school environment, Child abuse \& neglect 37.4, 2013, 243-251

[26] Konishi, Chiaki, et al, Do school bullying and student- teacher relationships matter for academic achievement? A multilevel analysis, Canadian journal of school psychology 25.1 2010, 19-39 https://doi.org/10.1177/0829573509357550

[27] Killen, Melanie, Adam Rutland, and Noah Simon Jampol, Social exclusion in childhood and adolescence, Handbook of peer interactions, relationships, and groups, 2009, 249-266

[28] Bonanno, Rina A., and Shelley Hymel, Cyber bullying and internalizing difficulties: Above and beyond the impact of traditional forms of bullying, Journal of youth and adolescence 42.5 2013, 685-697 https://doi.org/10.1007/s10964-013-9937-1

[29] Walrave, Michel, and Wannes Heirman, Cyberbullying: Predicting victimisation and perpetration, Children \& Society25.1, 2011, 59-72

[30] Van Vianen, Annelies EM, Betty AGW Dalhoeven, and Irene E. De Pater, Aging and training and development willingness: Employee and supervisor mindsets, Journal of Organizational Behavior 32.2, 2011, 226-247

[31] Aboujaoude, Elias, et al, Cyber bullying: Review of an old problem gone viral, Journal of Adolescent Health 57.1, 2015, 10-18

[32] eMarketer, Where in the World Are the Hottest Social Net- working Countries?,http://www.emarketer.com/Article/Where-World- Hottest-Social-NetworkingCountries/1008870, February 2012, Ac- cessed May 16th 2013

[33] Rybnicek, Marlies, Rainer Poisel, and Simon Tjoa, Facebook watchdog: a research agenda for detecting online grooming and bullying activities, Systems, Man, and Cybernetics (SMC), 2013 IEEE International Conference on, IEEE, 2013

[34] Singh, Vivek K., et al, They basically like destroyed the school one day: On Newer App Features and Cyber bullying in Schools, CSCW. 2017 https://doi.org/10.1145/2998 181.2998279

[35] Achenbach, T. M, Manual for the Youth Self-Report, University of Vermont, Department of Psychiatry, 2003

[36] Smith, P.K.,Mahdavi,J.,Carvalho, M.,Fisher, S.,Russell,S.,Tippett, N, Cyberbullying: Its nature and impact in secondary school pupils, Journal of child psychology and psychiatry 49.4, 2008, 376-385

[37] Slonje, Robert, Peter K. Smith, and Ann FriséN, The nature of cyber bullying, and strategies for prevention, Computers in human behavior 29.1, 2013, 26-32

[38] Aluede, Oyaziwo, et al, A review of the extent, nature, characteristics and effects of bullying behaviour in schools, Journal of Instructional Psychology 35.2, 2008, 151-159

[39] Ortega, Rosario, et al, The emotional impact on victims of traditional bullying and cyber bullying: A study of Spanish adolescents, Zeitschrift für Psychologie/Journal of Psychology217.4, 2009, 197 
[40] Hinduja, Sameer, and Justin W. Patchin, Bullying, cyber bullying, and suicide, Archives of suicide research 14.3, 2010, 206-221

[41] Bauman, Sheri, Russell B. Toomey, and Jenny L. Walker, Associations among bullying, cyberbullying, and suicide in high school students, Journal of adolescence 36.2, 2013, 341350

[42] Tokunaga, Robert S, Following you home from school: A critical review and synthesis of research on cyber bullying victimization, Computers in human behavior 26.3, 2010, 277 287

[43] Bryant, Clifton D., and Dennis L. Peck, eds, Encyclopedia of death and the human experience. Sage Publications, 2009 https://doi.org/10.4135/9781412972031

[44] Rutledge, Rebecca, The Everything Parent's Guide to Children with Depression: An Authoritative Handbook on Identifying Symptoms, Choosing Treatments, and Raising a Happy and Healthy Child. Simon and Schuster, 2007

[45] Schneider, Barry H, Child psychopathology: From infancy to adolescence. Cambridge University Press, 2014

\section{Authors}

Agathi Stathopoulou is a teacher in Secondary Education with a specialization in Greek philology. She holds a $\mathrm{PhD}$ in Special Education. She has taken part in research projects and seminars. At the current period is serving as a special educator at the Center for Diagnosis, Differentiation and Support, where pupils with special educational needs are assessed, in the B area of Athens. She is also a scientific associate at Net Media Lab of N.C.S.R. 'Demokritos'. She has written a book and articles in Greek and International journals.

Zoe Karabatzaki is a School Advisor at the 21st Preschool Educational Region of Athens. She holds a Ph.D. in Educational Sciences (Special Education). She has participated in many educational seminars and conferences as a keynote speaker and as instructor. Furthermore, she has taken part in research programs that were supported by many universities of Greece. She has written two books, chapters in collective volumes, articles in scientific journals and educational notes. She has taught at graduate and postgraduate programs at the University of Thessaly, at the University of Athens and at Democritus University of Thrace. She is also a scientific associate at Net Media Lab of N.C.S.R. 'Demokritos'.

Dionisis Loukeris is a Counsellor at the Ministry of Education, Research and Religious Affairs in Greece. He holds a PhD in "Environmental Education and Viable Growth" and a Master of Arts in "Theory and Practice of Teaching and Evaluation". He has been an Education Counsellor since 2004, first at the Institute of Educational Policy and then, until today, at the Ministry of Education, Research and Religious Affairs. He has taught at graduate and postgraduate programs at the University of Athens. He is also a scientific associate at Net Media Lab of N.C.S.R. 'Demokritos'. Writer of lots of books and research articles in Greek and international journals, he has also participated in conferences both in Greece and abroad.

Panagiotis Mantas is a Counsellor at the Ministry of Education, Research and Religious Affairs in Greece. He holds a Phd in Educational Sciences . From 2004-2012 he worked as an Education Counsellor for the Institute of Educational Policy in 
Greece. During his educational career, he has also taught among others at Intrainstitutional and Inter-Institutional-Interdepartmental Master studies for the University of Athens and the Piraeus University of Applied Sciences, the Democritus University of Thrace and the Institute of Informatics and Telecommunications, NCSR "Demokritos". He has written books and articles in Greek and International journals.

Georgia Kokkalia (MSc in Specific Learning Difficulties) is a Special Education Teaching Professional and Phd Candidate in University of Athens. She has participated in various research projects regarding the use of Information and Communication Technologies (ICTs) in Special Education and in Kindergarten

Athanasios Drigas is a director of research at N.C.S.R. Demokritos. He is the Coordinator of Telecoms Lab and founder of Net Media Lab since 1996. From 1985 to 1999 he was the Operational manager of the Greek Academic network. He has been the Coordinator of Several International Projects, in the fields of ICTs, and e-services (e-learning, e-psychology, e-government, e-inclusion, e-culture etc). He has published more than 300 articles, 7 books, 25 educational CD-ROMs and several patents. He has been a member of several International committees for the design and coordination of Network and ICT activities and of international conferences and journals.

Article submitted 08 January 2018. Final acceptance 02 February 2018. Final version published as submitted by the authors. 